\title{
Spectrum of Central Nervous System Tumours in a Tertiary Hospital of Bangladesh
}

\author{
SM Khodeza Nahar Begum, ${ }^{1}$ Masud Parvez, ${ }^{2}$ Mohammad Raziul Hoque, ${ }^{2}$ Omid Khan, ${ }^{3}$ Rita Rani Barua, ${ }^{4}$ Sahela Sultana ${ }^{4}$
}

\begin{abstract}
:
Background: Tumour registry data on intracranial and intraspinal tumours from a newly set up tertiary hospital of Bangladesh is presented here to provide substantial information about the current trends.

Materials \& methods: Hospital records of patients admitted under the neurosurgery service between January 2016 upto December 2017 were evaluated. Causes with a principal diagnosis of brain and spinal cord tumours were identified. Diagnosis with WHO grading and the histological subtypes are recorded.

Results: 86 cases of various tumours were retrieved out of total 98 neurosurgical cases. 70 of these tumours were of intracranial origin and 16 of intraspinal origin. Male to female ratio was approximately 1.28: I.The mean age of the patients was 45.9 years (range 3-75 years). Paediatric and adult patients accounted for $12.6 \%$ and $87.4 \%$ respectively. Most of the tumours were found in the $6^{\text {th }}$ decade. Paediatric intracranial tumours were predominately by medulloblastoma while adult population showed highest incidence of astrocytic tumours. Some rare entities were also encountered such as intracranial germinoma, Diffuse large $B$ cell lymphoma (DLBCL) and squamous cell carcinoma in a pre-existing intracranial epidermoid cyst.

Conclusions: Distribution of CNS tumour among this population gives a glimpse of the prevalence rate of such tumours in our community. This data can be linked to other national and international tumour registry for improved therapeutics and research.
\end{abstract}

Keywords: CNS tumours, astrocytic tumours, DLBCL, primary intracranial tumours.

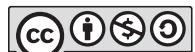

DOI: http://dx.doi.org/l0.3329/jom.v20il.388/9

Copyright: (C) 2019 Begum SMKN et al. This is an open access article published under the Creative Commons Attribution-NonCommercial-NoDerivatives 4.0 International License, which permits use, distribution and reproduction in any medium, provided the original work is properly cited, is not changed in any way and it is not used for commercial purposes.

Received: 06 June, 2018;

Accepted: 19 September, 2018

\section{Introduction:}

Tumours of central nervous system are rare and account for about 1 to $2 \%$ of all malignancies. However, their association with a high mortality and morbidity makes them the most dreaded form of cancer. ${ }^{1}$ Clinical presentation of brain tumour depends on the location, size of the tumours, and growth rate of the neoplasm. There is a high mortality and morbidity in these tumours irrespective of their histological grades. Glial tumours are the most common type of tumour arising from the brain parenchyma and include astrocytoma,

1. Professor of Pathology, Dr. Sirajul Islam Medical College and Senior Consultant, Bangladesh Specialized Hospital Ltd., Dhaka.

2. Department of Pathology and Laboratory Medicine, Bangladesh Specialized Hospital Ltd., Dhaka.

3. Department of Pathology and Laboratory Medicine, Bangladesh Specialized Hospital Ltd., Dhaka and Department of Endocrinology and Diabetes, Royal Wolvehamton NHS Trust, UK.

4. Department of Pathology, Dr. Sirajul Islam Medical College, Dhaka.

Corresponding author: Dr. SM Khodeza Nahar Begum, Professor of Pathology, Dr. Sirajul Islam Medical College and Senior Consultant, Bangladesh Specialized Hospital Ltd., Dhaka. khodeza33@hotmail.com. ependymoma, glioblastoma, oligodendroglioma and others. Nonglial tumours include embryonal tumours, choroid plexus tumours, pineal tumours, meningeal tumours, nerve sheath tumours, tumours of sellar region, hematopoietic neoplasm and metastatic tumours.

Each tumour has a distinctive biology, treatment and prognosis. ${ }^{2}$ These tumours may result in mental alteration and neurologic deficits, and the social burden. Therefore, an accurate understanding of the epidemiology is needed to facilitate early detection/treatment and prevention of CNS tumours.

Tumour registry data on intracranial and intraspinal tumours from a newly set up tertiary hospital of Bangladesh is presented here. This study implemented the latest $2016 \mathrm{WHO}$ classification system. The objective of this study was to provide substantial information about the current trends of central nervous system tumours in Bangladesh

\section{Materials \& methods:}

Study design

This study was taken at department of pathology, Bangladesh Specialized Hospital, Dhaka, which is a tertiary hospital and is an established referral centre for brain and spinal cord lesions. 
This was a retrospective study of primary and secondary brain tumour occurrence and its distribution pattern.

\section{Data collection \& analysis}

About 86 CNS tumour cases selected from January' 2016 up to December' 2017 were included. The sections were routinely stained with hematoxylin and eosin. In rare instances immunohistochemical stains were applied.

\section{Results:}

86 cases of various tumours are retrieved out of total 98 neurosurgical cases. 70 of these tumours were of intracranial origin and 16 of intraspinal origin. Male to female ratio was approximately $1.28: 1$. The mean age of the patients was 45.9 years (range 3 years upto 75 years). Paediatric and adult patients accounted for $12.6 \%(n=11)$ and $87.4 \%(n=75)$ respectively. Most of the tumours were found in the $6^{\text {th }}$ decade [Figure 1].

Paediatric intracranial tumours were predominated by Medulloblastoma while adult population showed highest incidence of astrocytic tumours.

The distribution of major histological types of brain tumour shown in the chart [Figure 2]. Meningioma accounts for about $27 \%$ of brain tumours. $30.4 \%$ of the meningiomas were of mixed type, while $26 \%$ were of meningothelial type. Rest of the meningiomas had incidence patterns like 13\% (syncytial, angiomatous and transitional each) and 4.3\% (Fibroblastic) respectively. Astrocytoma accounts for about $23 \%$ of brain tumours, majority (40\%) of which fell under WHO grade II. This is followed by Glioblastoma multiforme which represented 30\%.

Overall $37.2 \%$ of tumours were classified as WHO grade I, $7 \%$ as grade II, $1.2 \%$ as grade III and $12.8 \%$ as grade IV. About $41.9 \%$ of the cases were encompassing pituitary adenoma, Non-Hodgkin lymphoma etc.) remain unclassified with respect to WHO grading system. Following bar chart shows age wise distribution of WHO tumour grades. We observed that as age advances there is a higher incidence of lower grade tumours. Some rare entities are encountered

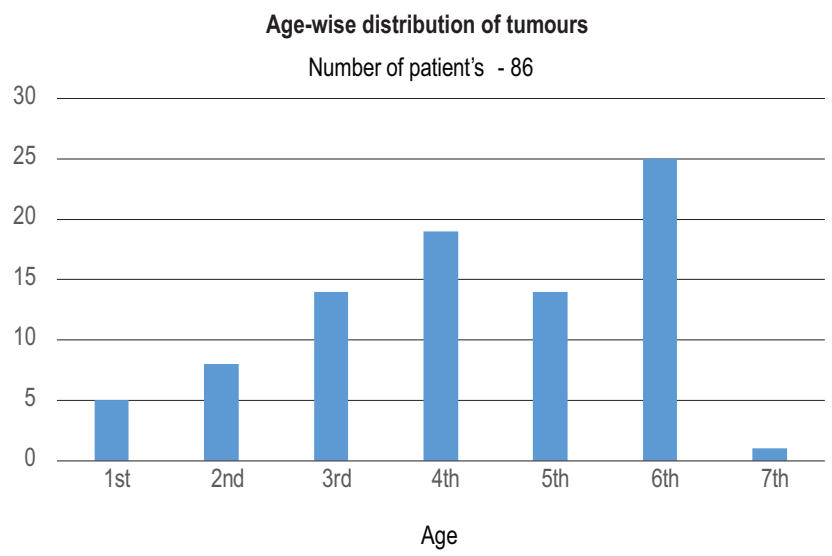

Figure 1. Age-wise distribution of different CNS tumours during this 2 year period such as Germinoma of pituitary gland [Figure 3], primary CNS non-Hodgkin lymphoma (DLBCL) in frontal lobe [Figure 4] and invasive squamous cell carcinoma arising from fronto-temporal epidermoid cyst.

Table I: Histological types of brain tumours

\begin{tabular}{|c|c|c|}
\hline Histological types of brain tumour & o. of cases & $\%$ \\
\hline \multicolumn{3}{|c|}{ Diffuse Astrocytoma \& Oligodendroma tumours } \\
\hline Diffuse astrocytoma & 7 & 8.1 \\
\hline Anaplastic astrocytoma & 1 & 1.1 \\
\hline Glioblastoma & 8 & 9.3 \\
\hline \multicolumn{3}{|l|}{ Other Astrocytic tumour } \\
\hline Pilocytic astrocytoma & 4 & 4.6 \\
\hline \multicolumn{3}{|l|}{ Ependymal tumours } \\
\hline Ependymoma & 2 & 2.3 \\
\hline Subependymoma & 1 & 1.1 \\
\hline \multicolumn{3}{|l|}{ Embryonal tumour } \\
\hline Medulloblastoma & 5 & 5.8 \\
\hline \multicolumn{3}{|l|}{ Tumours of the cranial and peripheral nerves } \\
\hline Schwannoma & 14 & 16.3 \\
\hline Neurofibroma & 2 & 2.3 \\
\hline \multicolumn{3}{|l|}{ Meningeal tumour } \\
\hline Meningioma & 23 & 26.7 \\
\hline \multicolumn{3}{|l|}{ Mesenchymal. Non-menigiothelial } \\
\hline Diffuse large B-cell lymphoma & 1 & 1.1 \\
\hline Primary intracranial squamous cell carcinoma & la 1 & 1.1 \\
\hline Capillary hemangioma & 1 & 1.1 \\
\hline \multicolumn{3}{|l|}{ Tumour of the sellar region } \\
\hline Craniopharingioma & 1 & 1.1 \\
\hline Pituitary adenoma & 12 & 13.9 \\
\hline Germinoma of pituitary gland & 1 & 2 \\
\hline \multicolumn{3}{|l|}{ Secondary } \\
\hline Metastatic RCC & 1 & 1.1 \\
\hline Metastatic adenocarcinoma & 1 & 1.1 \\
\hline
\end{tabular}

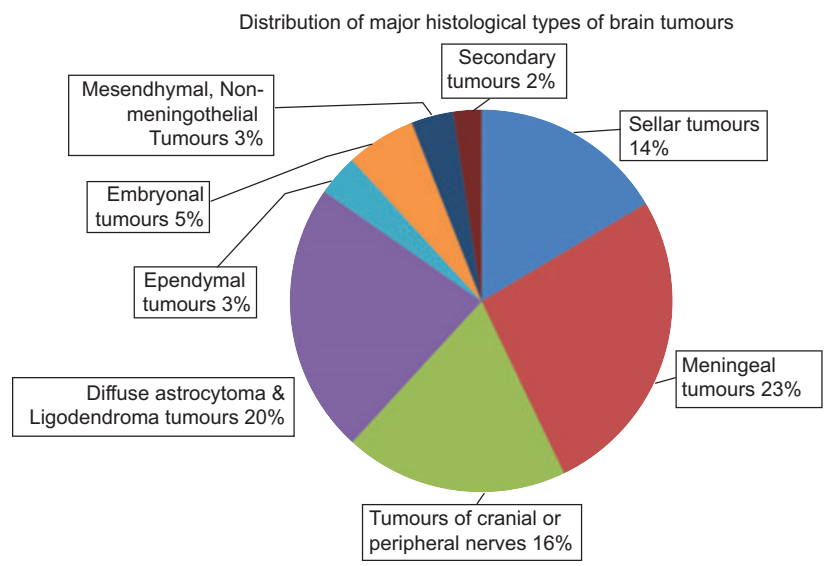

Figure 2. Major histological types of CNS tumours 

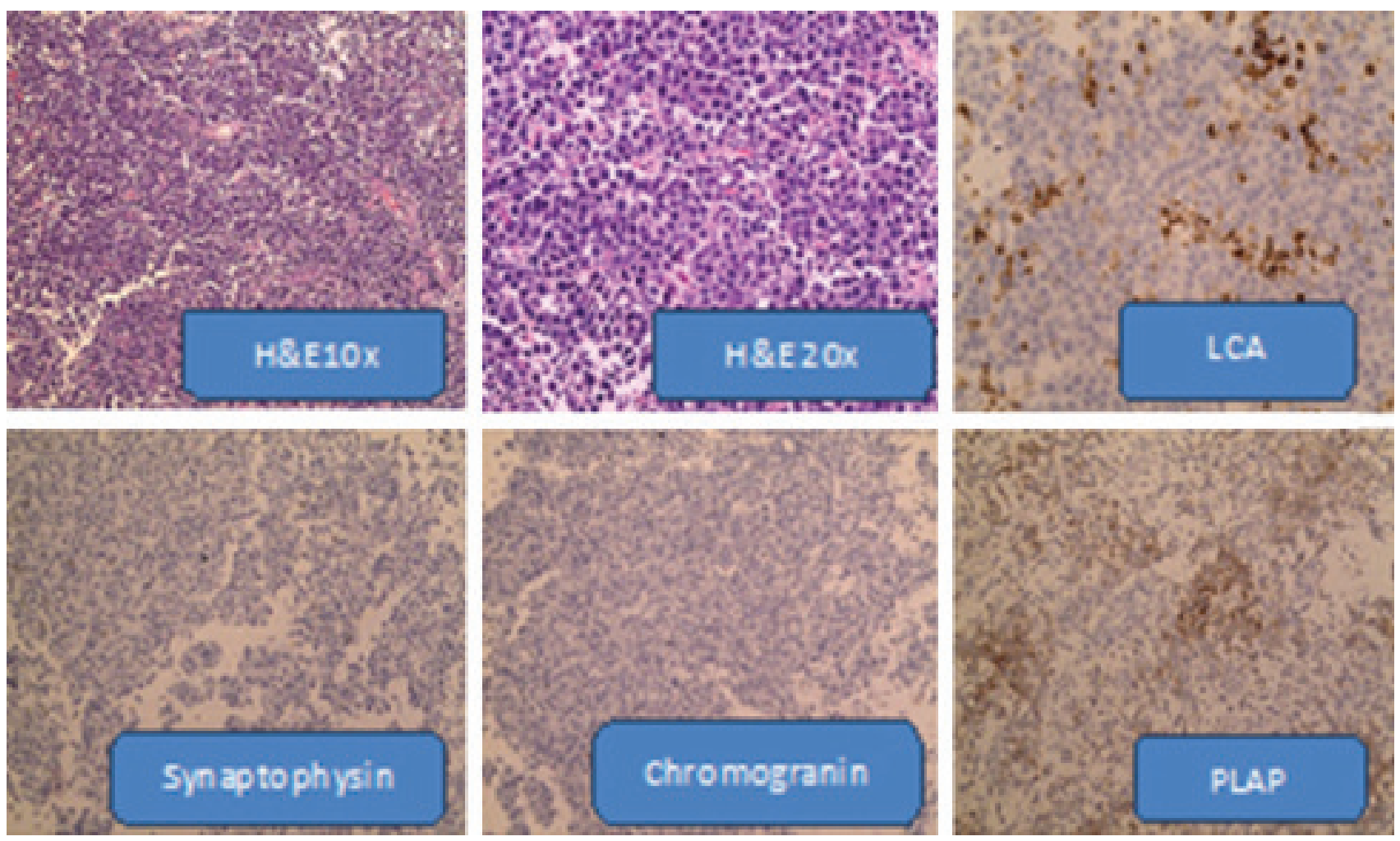

Figure 3. Germinoma of pituitary gland
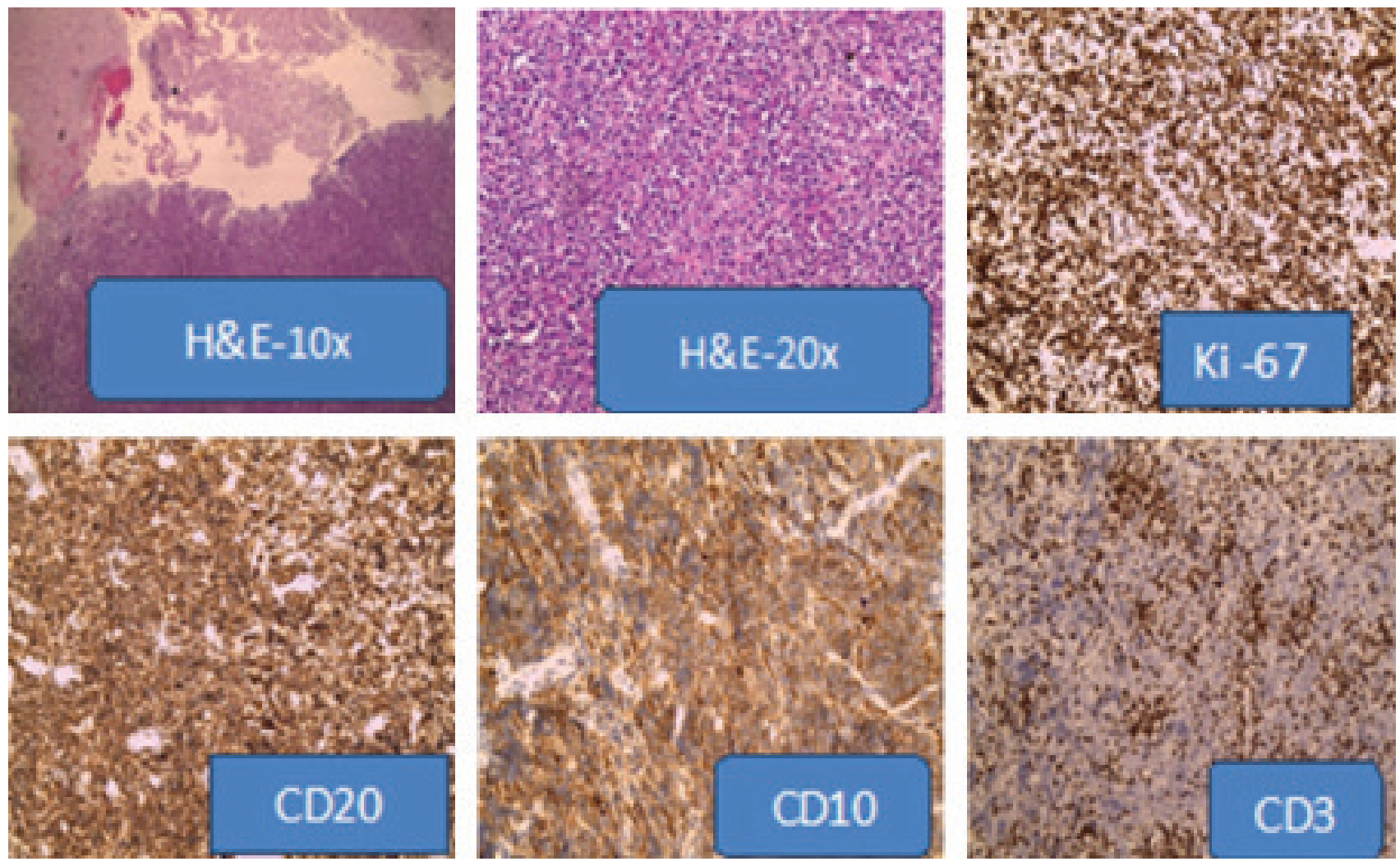

Figure 4. Primary CNS Non-Hodgkin lymphoma (DLBCL) 


\section{Discussion:}

Among the 86 cases of brain tumour in our study, we found $37(43 \%)$ cases in in the group of $41-60$ years. Peak age group in our study was 51-60 years, accounting for $25(29 \%)$ cases. Some authors however reported peak age incidence between $40-50$ yrs. $3,4,5$

We found meningioma as the most common lesion $(n=23,26.7 \%)$. Astrocytic tumours were the second commonest ( $\mathrm{n}=20,23.3 \%)$, supporting previous studies. ${ }^{3,5,6}$ Sajeeb $\mathrm{M}$ et al. however found Astrocytoma as the most common subtype. ${ }^{7}$

Sex preponderance among our cases diagnosed with meningioma were higher in females (M: $\mathrm{F}=1: 2.28)$ which corresponds to many other previous studies. ${ }^{8,9}$ Astrocytoma, however was significantly higher among males (M: $\mathrm{F}=5.66: 1$ ). This finding is also supported by previous findings. ${ }^{10,11}$

Pituitary adenoma constituted $13.9 \%$ of all tumours. This is compatible with other similar studies. ${ }^{12,13,14}$

Our study has generated some corroborating patterns and interesting insights into the prevalence of primary CNS tumours. We encountered some rare cases also within this period. Two cases of metastatic carcinomas were also encountered. One is renal cell carcinoma metastatic into frontal lobe of brain and the other is a metastatic adenocarcinoma of unknown primary into spinal cord at D2.

\section{Conclusions:}

This data from a single hospital giving a glimpse of the varied incidence of central nervous system tumours, is limited in usage. In-depth studies from across various hospitals in national and international level can be linked to this data for improved therapeutics and better research.

\section{Acknowledgement:}

We thank the histotechnologists and the IT specialists of Bangladesh specialized hospital for their immense support and sincere efforts while executing this study.

\section{Conflict of interest: None.}

\section{References:}

1. Lacy J, Saadati H, Yu JB. Complication of brain tumours and their treatment. Hematol Oncol Clin North Am 2012;26:779-796. https://doi.org/10.1016/j.hoc.2012.04.007
2. Idowu O, Akang E, Malomo A. Symptomatic primary intracranial neoplasm in Nigeria. West Afri J Neurosci (Turk) 2007;19(24):212-218.

3. Lee CH, Jung KW, Yoo H, ParkS, Lee SH. Epidemiology of primary brain and central nervous system tumours in Korea. J Korean Neurosurg Soc 2010;48:145-152. https://doi.org/ $10.3340 / \mathrm{jkns} .2010 .48 .2 .145$

4. Dhar A, Bhat AR, Nizami FA, Kirmani AR, Zargar J, Ramzan AU, et al. Analysis of brain tumours in Kashmir Valley- A 10-year study. Bangladesh J Med Sci 2014;13:268-277. https://doi.org/10.3329/bjms.v13i3.19148

5. Ghanghoria S, Mehar R, Kulkarni CV, Mittal M, Yadav A, Patidar H. Retrospective histological analysis of CNS tumours - A 5-year study. Int J Med Sci Public Health 2014;3:12051207. https://doi.org/10.5455/ijmsph.2014.080720141

6. Das A, Chapman CA, Yap WM. Histological subtypes of symptomatic central nervous system tumours in Singapore. J Neurol Neurosurg Psychiatry 2000;68:372-374. https:// doi.org/10.1136/jnnp.68.3.372

7. Sajeeb M, Rajashree P, Subrata P et al.Clinicopathological pattern of brain tumours: A three year study in a tertiary care hospital in India.Clin Cancer Investig J 2016;5:437440. https://doi.org/10.4103/2278-0513.197861

8. Surawicz TS, McCarthy BJ, Kupelian V, Jukich PJ, Bruner JM, Davis FG. Descriptive epidemiology of primary brain and CNS tumours: results from the Central Brain tumour Registry of the United States, 1990-1994. Neuro Oncol 1999;1(1):14-25. https://doi.org/10.1093/neuonc/1.1.14

9. Wiemels J, Wrensch M, Claus EB. Epidemiology and etiology of meningioma. J Neurooncol. 2010;99(3):307-314. https:// doi.org/10.1007/s11060-010-0386-3

10. Yusoff MR, Abdullah JM, Isa MN. Brain tumours in Rural North East Malaysia. Med J Islam Acad Sci. 1998;11(4):121129.

11. Bondy ML, Scheurer ME, Malmer B, et al. Brain tumour Epidemiology; Consensus from the brain tumour Epidemiology Consortium (BTEC).Cancer. 2009;113(713): 1953-1968.

12. Chaegbulam SC, Saddeqi N, Ikerionwu S. Intracranial tumours in Enugu,Nigeria. Cancer 1980;46(10):2332-2334.

13. Adekye A. Neoplasia of the brain in the africans. Surg Neurol 1970;11:247-255.

14. Monga K, Gupta VK, Gupta S, Marwas K. Clinicopathological study and epidemiological spectrum of brain tumours in Rajasthan. Indian J Basic Appl Med Res 2015;5:728-734. 